\title{
A MODEL FOR OPTIMIZING THE WORK OF ETHICS COMMITTEES IN THE HEALTHCARE SYSTEM IN BULGARIA: AN INSTRUMENT FOR MORE EFFECTIVE DISTRIBUTION OF HEALTHCARE SERVICES
}

\author{
Petya Trendafilova* \& Neli Gradinarova**
}

\begin{abstract}
Achieving a positive result in creating a model for optimizing the work of ethics committees in the healthcare system in Bulgaria is based on an indepth analysis of the established international experience in implementing ethics committees as well as the current national practice in solving case studies of relevant ethics committees operating on the territory of the country. A survey was conducted to examine the opinion of medical professionals on their awareness of the existence of an ethics committee in their health care facility; The awareness of the specialists about the functions, power and activities of the ethics committee in the medical establishment; The interaction of the medical specialists at the hospitals with the Ethics Committee; The need to introduce training of the medical specialists within the hospitals on topics considered by the Ethics Committee. A model for optimizing the activities of ethics committees in the healthcare system in Bulgaria has been developed. Members of Ethics Committees in Bulgaria should be actively involved in the training of researchers and all categories of specialists and non-specialists involved in clinical research, drawing on experience from participating in a European Research Infrastructure Consortium (ERIC).
\end{abstract}

INTRODUCTION

\section{INTRODUCTION}

As early as in the 1950s, issues such as whether there are ethical limits that should not be crossed or scientific and technological development

\footnotetext{
* Petya Trendafilova, Associate Professor of Health Technology Assessment, Faculty of Public Health, Medical University-Sofia, Bulgaria. Research fields: HTA, Health Policy and Health Services Research, Injury and Violence Prevention.

${ }^{* *}$ Neli Gradinarova, Chief Assistant Professor of Health Law, Department of Medical Ethics and Law, Faculty of Public Health, Medical University-Sofia, Bulgaria. Research fields: Health Law, Health Regulations, Health Policy and Health Services Research.
} 
destroy traditional values, engage in intense debate with the involvement of professionals from different fields, as a result of which is formed the modern medical ethics. ${ }^{1}$

Moral issues are the subject of a public debate outside the narrow limits of the medical profession. ${ }^{2}$

Ethical committees in medical settings are based on the principles of medical ethics and medical law and have several basic functions: preparing opinions on patients' complaints or their representatives, as well as carrying out checks on unethical relationships between hospital staff and patients or between them and the students and specialists in the health care facility. ${ }^{3}$

They are committed to drafting opinions and monitoring compliance with the legal requirements for clinical trials of medicines, medical equipment and medical supplies.

The legal regulation of the activities of these committees is not exhaustive, as there are conflicting practices in the activities of the commissions to the various medical institutions in the country. That is why we think it is necessary to create a model for optimization of their activities. It can serve as a basis for synchronizing the activities of ethics committees in the healthcare system in Bulgaria, which would improve the quality of assessment of ethical behavioral norms in healthcare establishments and improve the quality of the medical activity performed within the healthcare establishments in the country.

Research programs implemented within the EU are adopted without prejudice to the Member States' research activities. The reason is that under primary EU law-the Lisbon Treaty, there is parallel competence in research. In accordance with Article 4 (3) TFEU,

in the areas of research, technological development and space, the Union has competence to take action, in particular to develop and implement programs, the exercise of which is not such as to prevent States Member States to exercise their competence.

The approach taken in the Horizon 2020 EU Research and Innovation Program is in line with the social challenges and is geared towards addressing the main concerns that cause concern among the citizens of Europe and other parts of the world. For healthcare, this includes, for

\footnotetext{
${ }^{1}$ Bernard Lo, MD, FACP, Resolving Ethical Dilemmas: A Guide for Clinicians (4TH Edition) 6 (Lippincott Williams \& Wilkins, a Wolters Kluwer business, ISBN-13: 978-0-7817-9379-7, ISBN-10: 0-7817-9379-3, 2009).

${ }^{2}$ H. Biggs, Healthcare Research Ethics and Law Regulation, Review and Responsibility 117 (Published by Routledge-Cavendish, 2010).

${ }^{3}$ S. Derr, Hospital Ethics Committees: Historical Development, Current IsSue, AND RECOMMENDATIONS 216 (Biblio Bazaar, ISBN 1244038954, 2011).
} 
example, research into cancer, diabetes, Alzheimer's disease and Parkinson's disease. In the implementation of its research programs, the Commission shall not publish calls for proposals specifically for research on human embryonic stem cells. On the bottom-up principle, scientists themselves offer the best possible approaches for carrying out a particular research. Research projects at EU level also include projects that may provide for the comparison of different types of cells, including human embryonic stem cells and induced pluripotent stem cells, leaving a wide field for scientific research in the light of scientific progress.

The attitude towards patients and participants in clinical trials shows the existence in Bulgaria of communication difficulties, putting a certain group of people in a disadvantaged position compared to other members of society. This calls for targeted and consistent action through the deepening of research and the promotion of health education and the realization of innovative research projects with a focus on bio-ethical aspects in the provision of medical activity.

\section{ANALYSIS AND DISCUSSION}

The analysis of the regulation of the activities of ethics committees in the healthcare systems within the EU and in the health system in Bulgaria shows that there is a need to optimize the activity of ethics committees operating on the territory of the country.

Based on our analysis, a model for optimizing the work of ethics committees in the healthcare system in Bulgaria has been prepared: Concerning Ethical Commissions for Clinical Trials ${ }^{4}$.

Table 1 Assisting in the implementation of activities prior to the start of the study.

\begin{tabular}{lll}
\hline Stage & Role of the ethical commission & \\
\hline 1 & Planning and preparation of projects & $\begin{array}{l}\text { Providing information according to the needs of } \\
\text { the research team }\end{array}$ \\
2 & Review of the relevant documentation & Ethical evaluation of the project proposal \\
\hline
\end{tabular}

Table 2 Assistance in implementing activities after the start of the study.

\begin{tabular}{lll}
\hline Stage & Role of the ethical commission & \\
\hline 1 & Implementation of the study & $\begin{array}{l}\text { Project follow-up to a specific ethical aspect } \\
\text { (possibility of re-evaluation-if necessary) }\end{array}$ \\
2 & Completion of the study & $\begin{array}{l}\text { Review of the reports perpared by the research } \\
\text { team on th basis of the survey }\end{array}$ \\
\hline
\end{tabular}

\footnotetext{
${ }^{4}$ Градинарова Н., Модел за подобряване дейността на етичните комисии в системата на здравеопазването в България. Автореферат, 63 стр (2017).
} 


\section{Concerning Ethical Committees in Hospital Health CARE SETTINGS 5}

1. Organize and hold regular training sessions (ex. once a month) with the staff of the health care facility.

Regular meetings can discuss both general theoretical issues related to the ethics committee's work and practical aspects of everyday practice. Through presentations the audience can be acquainted with the main functions and competencies of the ethics committee, and by solving practical cases, the staff of the medical establishment will be able to put themselves in a real situation.

2. Conducting a survey of the healthcare staff on the level of awareness; the nature of the issues of interest to the providers of medical services; as well as the ability to deal with conflict situations and solve problems in bioethics.

Performing a survey would increase the level of awareness among members of ethics committees as well as health care managers about the ethical issues and challenges faced by medical staff at the health care facility.

The results of such a study could serve as a basis for developing training panels for the different categories of staff involved in the provision of medical services.

3. Targeting annual objectives to be achieved through the work of the ethics committee in order to improve the awareness and quality of medical activity in the health care facility.

The formulation of annual objectives to be attained by the Ethics Committee implies a periodic evaluation of the Committee's work, thus clearly showing progress towards the objectives set.

4. The implementation of training and practical activities by the members of the ethics committee within a pre-approved monthly schedule for visits of individual clinics and wards within the medical establishment.

By establishing an individual monthly schedule of commitment of the individual members of ethics committees, the representatives of the individual clinics and wards in the structure of the medical institution will be given the opportunity to bring to the attention of the commission specific issues related to the specific medical field, in which the specific structural Unit provides medical care.

5. Representatives of the Ethics Committee to monitor the activity of the individual structural units within the medical establishment in connection with recommendations and prescriptions issued to limit and

\footnotetext{
${ }^{5}$ Ibid.
} 
prevent cases of unethical and immoral behavior by employees.

The specific prescriptions and recommendations should reflect the specifics of the medical activity, the types of specialists working in the clinic/department and the contingent of patients seeking medical care at the relevant unit of the medical establishment.

6. Preparation of information materials (brochures, prospectuses) intended for patients, their family members and their escorts, the decisionmaking stages of the medical-diagnostic activity, as well as the ethical aspects and problems that may arise in connection with the provision of medical services within the medical establishment.

The introduction of information materials into the day-to-day service of patients in the hospital would facilitate the communication between the staff of the medical establishment and the patients and their relatives, as this kind of initiative would also have a preventive character in view of the issues raised before the ethics committee of the medical settings. When the patient is aware of the options available to him to resolve ethical conflicts, this would limit the indiscriminate referral to the Ethics Committee, especially in cases where they are not factually and legally complex.

7. Development and introduction of a short specialized training panel for nurses working in hospitals.

The necessity of introducing a specialized Nursing Training Panel stems from the fact that, in a significant percentage of cases, the nurse initially contacts the patient and/or his or her relatives, and usually the patients usually refer to the nurse for assistance on matters of any kind.

Through the introduction of a dedicated training panel, it is possible to prevent many conflicts between patients and medical professionals based on an ethical basis.

The preparation of a training panel should be based on a preliminary study (through a questionnaire) among nurses on the nature of the issues that are being addressed by them.

\section{CONCLUSION}

Members of ethics committees in Bulgaria should be actively involved in the training of researchers and all categories of specialists and nonspecialists involved in clinical research, drawing on experience from participating in a European Research Infrastructure Consortium (ERIC).

The current legislation allows only a certain range of medical, biological and other research to be regulated, which requires the synchronization of the existing ethics committees with the medical 
institutions in Bulgaria and the elaboration of a model for optimizing their activities.

In order to raise awareness of the role, functions and powers of ethics committees established within the country, it is necessary to lay down a more detailed regulation. There are cases where it is possible to draw up unified recommendations to achieve synergy in the work of the different types of ethics committees.

The attitude towards patients and participants in clinical trials shows the existence in Bulgaria of communication difficulties, putting a certain group of people at a disadvantage compared to other members of society. This requires targeted and coherent action through the deepening of research and the promotion of health education and the implementation of innovative research projects with a focus on bio-ethical aspects in the provision of medical activity. 